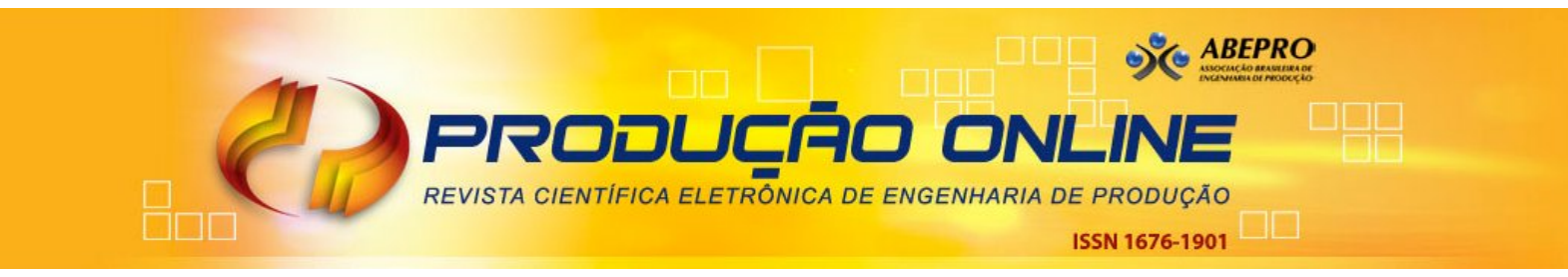

\title{
MODELO DE GESTÃO DE RISCOS EM LAVANDERIAS DE BENEFICIAMENTO NO ARRANJO PRODUTIVO LOCAL (APL) TÊXTIL E DE CONFECÇÕES DE PERNAMBUCO, BRASIL
}

\section{RISK MANAGEMENT MODEL IN BENEFIT LAUNDRIES IN THE LOCAL TEXTILE PRODUCTIVE ARRANGEMENT (LPA) OF PERNAMBUCO, BRAZIL}

\author{
Emmanuelle M. G. Lorena* E-mail:emmanuelle@lorenas.com.br \\ Cynthia M. G. Lorena** E-mail:cynthia@lorenas.com.br \\ Raimundo M. Medeiros* E-mail: mainarmedeiros@gmail.com \\ Soraya G. El-Deir* E-mail:sorayageldeir@gmail.com \\ Romildo M. Holanda* E-mail:romildomorant@gmail.com \\ Vinícius D. Araújo* E-mail: vicodantas@yahoo.com.br \\ *Universidade Federal Rural de Pernambuco (UFRPE), Recife, PE \\ **IPOG - Especialização em Design de Interiores - Ambientação e Produção do Espaço
}

\begin{abstract}
Resumo: Os riscos ambientais inerentes ao processo de lavagem e beneficiamento têxtil são considerados um fator negativo ao Arranjo Produtivo Local do Agreste pernambucano. A produção gera contaminação nos corpos hídricos, no solo e no ar; além de desequilíbrio no ecossistema, por desmatamento da flora nativa; como também da feição social, por exposição dos trabalhadores a danos potenciais à saúde. $\mathrm{O}$ objetivo desse estudo consiste em estabelecer modelo de gestão de riscos em lavanderias de beneficiamento no APL têxtil e de confecções do Agreste de Pernambuco, baseado na ISO 31.000:2009, ocorrendo nos mês de novembro e dezembro de 2016, numa unidade fabril na cidade de Caruaru. O modelo foi estabelecido com o emprego de ferramentas como, relatório fotográfico, entrevista semi-estruturada, brainstorming, mapeamento de processo e priorização de ações por meio da matriz GUT e concepção de mapa de riscos em layout. Como resultado, foi possível estabelecer um modelo aplicado à indústria têxtil no segmento de lavagem de jeans com aderência as características locais. Para a validação do modelo, o mesmo foi aplicado à lavandeira em estudo, obtendo assim, dados quanto à identificação dos riscos demonstrando que os processos com maiores concentrações são o de lavagem e de geração de vapor $(45,3 \%)$, sendo os riscos ecológicos como maior representatividade (51\%). Conclui-se que o modelo estabelecido, mesmo que preliminarmente, foi avaliado como satisfatório, visto o cumprimento das etapas pré-estabelecidas. Porém, a gestão dos riscos não deve ser executada uma única vez, sendo necessário acompanhamento.
\end{abstract}

Palavras-chave: ISO 31000. Impacto ambiental. Jeans.

\begin{abstract}
The environmental risks inherent in the textile washing and processing process are considered to be a negative factor in the Local Productive Arrangement of the Agreste region of Pernambuco. The production generates contamination in the water bodies, in the soil and in the air; besides imbalance in the ecosystem, by deforestation of the native flora; as well as the social aspect, due to exposure of workers to potential health damages. The objective of this study is to establish a risk management model in the laundry processing and textile APL garments in the Agreste of Pernambuco, based on ISO 31,000:2009, occurring in November and December 2016, at a plant in the city of Caruaru. The model was established with the use of tools such as, photographic report, semi-structured interview, brainstorming, process mapping and prioritization of actions through the GUT matrix and design of risk map in layout. As a result, it was possible to establish a model applied to the textile industry in the segment of jeans washing with adherence to the local characteristics. For the validation of the model, it was applied to the lavandeira under study, thus obtaining data on the identification of the risks, demonstrating that the processes with the highest concentrations are washing and steam generation (45.3\%), with the risks (51\%). It is concluded that the established model, even if preliminarily, was evaluated as satisfactory, considering the fulfillment of the pre-established steps. However, risk management should not be performed only once and follow-up is required.
\end{abstract}

Keywords: ISO 31000. Environmental impact. Jeans.

Revista Produção Online. Florianópolis, SC, v. 18, n. 2, p. 620-640, 2018. 


\section{INTRODUÇÃO}

Os riscos ambientais inerentes ao processo de lavagem e de beneficiamento têxtil são considerados um fator negativo ao Arranjo Produtivo Local (APL) de confecções do Agreste pernambucano, nordeste do Brasil. Uma vez que, essas indústrias são insuficientes quanto às questões sociais como às ecológicas, pois causam poluição hídrica, sólida e atmosférica e colabora para degradação da flora nativa brasileira, o que se acentua quando alinhadas a uma grande concentração de indústrias no mesmo território, a exemplo da cidade de Caruaru-PE, que apresenta quantitativo relevante de lavanderias têxtil no $A P L$ (BRITO, 2013; ROCHA, SILVA JUNIOR, VIANA; 2015).

Consoante, os processos produtivos de beneficiamento de jeans geram contaminação nos corpos hídricos e no solo, aumentados por descargas químicas oriundos da destinação inadequada de resíduos; no ar, por emissão de gases poluentes da queima de lenha; além de desequilíbrio no ecossistema, por desmatamento da flora nativa; e da feição social, por exposição dos trabalhadores a danos potenciais à saúde (SILVA; BARROS; REZENDE, 2005).

Visto que a legislação brasileira estabelece diretrizes para o diagnóstico-problema, por meio da Resolução Conama n. 1, que dispõe sobre critérios para avaliação de impactos e premissa para o licenciamento ambiental (CONAMA, 1986). Tais critérios também são objeto da Portaria SSST n. 25 do Ministério do Trabalho, no tocante ao reconhecimento, à avaliação e ao controle dos riscos ambientais relativos à integridade de funcionários (MTE, 1994).

Assim, a aplicação de modelos de gestão de riscos tende a melhorar o nível da segurança dos funcionários, pois promove a minimização da probabilidade de acidente ou de consequências, por meio da aplicação de metodologia de análise e de avaliação desses, além de identificar o problema (PYRGIDIS; PAPACHARITOU; ELEFTHERIADIS, 2016). Rehacek (2017) afirma que o gerenciamento é universal, mas na maioria das circunstâncias uma atividade desestruturada.

Segundo Olechowski et al. (2016), a norma ISO 31000 é uma diretriz para a estabelecimento da gestão de riscos em projetos e em processos, além de fatores como redução de custos, atendimento de prazos e de resultados técnicos. Além disto, itens como segurança também podem ser alcançados pelas organizações. Tal normativa deve ser observada visando o estabelecimento de procedimentos mais seguros para o bom funcionamento das empresas. 
Dessa forma, o objetivo desse trabalho consiste em estabelecer modelo de gestão de riscos em lavanderias de beneficiamento no APL têxtil e de confecções do Agreste de Pernambuco. Tal definição tem por motivação auxiliar na sustentabilidade socioambiental do setor, além de estabelecer parâmetros para a excelência setorial.

\section{REVISÃO DE LITERATURA}

O risco trata-se de toda eventualidade que se receia ou que se teme, sendo a probabilidade de que um evento se torne realidade, sendo a possibilidade da materizalização do perigo ou de um evento indesejado, quanto que o perigo é a fonte ou situação potencial para provocar danos a saúde do trabalhador ou ao meio ambiente, correspondendo à causa em que o risco deixa de estar latente para se passar a manifestar, se tratando de um agente químico, biológico ou físico ou um conjunto de condições (CONAMA, 1986; MTE, 1994; ABNT, 2009).

Segundo Yuan et al. (2017) o gerenciamento de riscos consiste em um trabalho que aborda as características do risco e a maneira de como lidá-lo por meio de avaliação e mitigação. Para Rehacek (2017) o gerenciamento de risco pode ser definido como atividades coordenadas para direcionar e controlar uma projeto em relação ao risco.

Dessa forma, medidas para o controle da ocorrência dos riscos devem ser tomadas, por meio de técnicas adequadas de análise de riscos e procedimentos de determinação de contingência em projetos de construção melhora a eficiência e eficácia do projeto, fazendo o emprego da gestão de riscos (ABNT, 2009; ELBARKOUKY et al., 2016). A NBR ISO 31.000 apóia as organizações para a gestão de riscos por meio de um modelo que contempla desde a identificação, análise, avaliação até o monitoramento dos riscos (ABNT, 2009).

No qual, a identificação de riscos é o processo que se propõe a determinação os riscos ao longo do ciclo de vida de um projeto ou produto, com o objetivo principal de documentar os riscos identificados (REHACEK, 2017). Para Oliveira et al. (2017) a identificação de riscos visa listar os riscos e as diferentes origens, as casuas e as possiveis consequências e as áreas afetadas, quanto que a análise do risco visa a compreensão do risco para promover a melhor ação e utilização do método adequado, considerando as causas e as fontes.

Conforme Rehacek (2017) a análise qualitativa do risco é o processo de priorização por meio da combinação da probabilidade de ocorrência e impacto, no qual o principal 
benefício é que permite a tomada de decisão para a redução do nível de incerteza. Serpa (2000) classificação dos riscos ambientais quanto ao tipo e ordenamento de prioridades, em Riscos de Segurança de Processos (RSP) quando são ocasionados atividades, instalações e equipamentos, Risco à Saúde Humana (RSH), quanto da eventualidade de ocorrência de doenças por exposição a contaminantes e Risco Ecológico (RE) e quando geram efeitos aos ecossistemas, também denominados como impactos ambientais.

Esse agrupamento fornecer mais apoio para a tomada de decisões, avaliando os riscos que precisam de tratamento e a prioridade de implementar esse tratamento (OLIVEIRA, et al. 2017). Assim, a avaliação de riscos consolida exposição e vulnerabilidade ao risco por meio de mapas que podem utilizar com métodos qualitativos e quantitativos (Yuan et al.; 2017).

Krzemien et al. (2016) afirmam que os riscos podem ser considerados em duas categorias, Riscos Potenciais (RP) e Riscos Insignificantes (RI), concedendo uma alternativa para a supressão dos riscos menores, concentrando-se nos mais importantes considerados, os como maior pontencial de ocorrência (RP). O monitoramento deve ocorrer após a definição dos riscos e sua classificação e priorização, por meio de medidas corretivas e preventivas (ABNT, 2009).

\section{METODOLOGIA}

O estudo deu-se nos meses de novembro e dezembro de 2016, numa unidade de lavagem e beneficiamento têxtil, no município de Caruaru, localizado a aproximadamente 135 km da capital do estado de Pernambuco, inserida no APL têxtil (Figura 1). 
Figura 1 - Localização do município de Caruaru no APL têxtil do agreste pernambucano

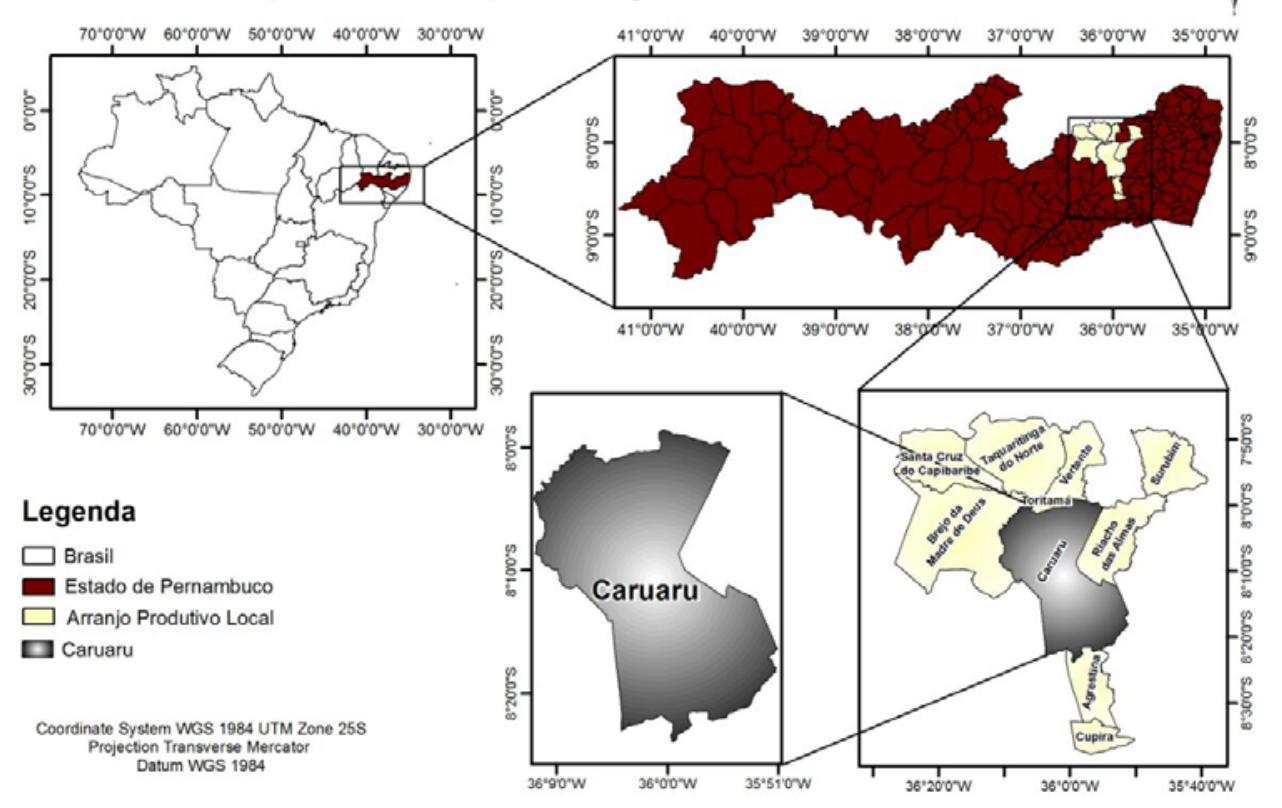

Fonte: autor

A lavanderia estudada dispõe de área de instalações de cerca de $2.000 \mathrm{~m}^{2}$, com produção média semanal de 6.000 peças de jeans, classificada como empresa de pequeno porte pelo cadastro de Cadastro Nacional de Pessoa Jurídica (CNPJ). Estando legalmente constituída, possui quadro funcional com 32 funcionários, sendo três colaboradores da área administrativa. Os funcionários fazem uso de fardamento e Equipamentos de Proteção Individual (EPI), sendo a segurança do trabalho gerida por empresa terceirizada de consultoria. Quanto à infraestrutura, conta com maquinário para lavagem, secagem, centrifugação das peças e caldeira para geração de vapor, com manutenção preventiva programada anualmente. Quanto aos resíduos, apresenta uma estação de tratamento primário de efluente e área composta de leito de secagem de lodo, além de área de $16 \mathrm{~m}^{2}$ de área destinada a estocagem provisória do lodo. Os resíduos sólidos finais deste processo são destinados a um aterro sanitário.

Durante o processo a indústria faz uso de um quantitativo de 100 produtos químicos, contados pelo número de Ficha de Informações de Segurança de Produtos Químicos (FISPQ), atualmente disponíveis para aquisição por parte da empresa.

A fonte energética empregada pela lavanderia advém da concessionária local para as instalações dos equipamentos do processo, além do uso de lenha para a queima na caldeira. A energia térmica proveniente da queima da lenha é consumida no aquecimento da água, que será utilizada nos processos de lavagem (BRITO, 2013).

A metodologia foi agrupada em três etapas por meio dos requisitos estabelecidos pela ABNT NBR ISO 31.000:2009, contemplando as normas de princípios e diretrizes para Revista Produção Online. Florianópolis, SC, v. 18, n. 2, p. 620-640, 2018. 
a gestão de riscos proporcionando a identificação, análise e avaliação, etapas consideradas satisfatórias para o estabelecimento de um modelo de gestão de riscos (Figura 2).

Figura 2 - Modelo de gestão de risco aplicado.

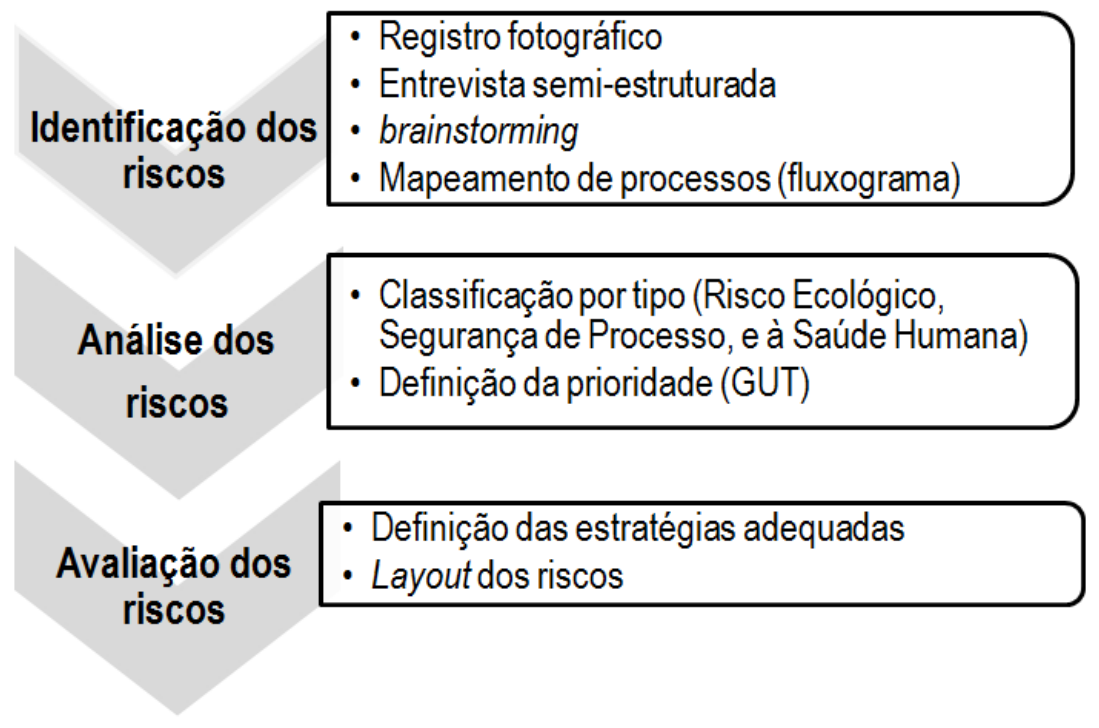

Fonte: autor

A maior parcela dos modelos de gestão de riscos inicia com a identificação dos riscos, como um ponto de partida para o seu gerenciamento (SILVA et al., 2017).

\section{Etapa 1 - Identificação de riscos}

No primeiro momento realizou-se um levantamento de dados, por meio de registros fotográficos e entrevistas semi-estruturadas com roteiro temático desenvolvido por temas geradores, subsidiando novos questionamentos, a partir das respostas informadas (TRIVIÑOS, 1987). Tal procedimento foi complementado com a utilização de brainstorming com os funcionários, técnica que estimula o raciocínio criativo, gerando uma maior alternativa de idéias, focalizado no tema estudado (ALVES, 1995).

A partir disso, empregaram-se técnicas de mapeamento de processo e gerou-se um fluxograma no Microsoft Visio 2013, fornecendo uma representação gráfica das fases que compõem um processo, de forma a permitir uma visão global e das características que compõem as etapas, levando em consideração as entradas e saídas (PMI, 2013). Para o a identificação das entradas do processo, foram apontadas a presença de metais pesados por meio de leitura das composições químicas existentes nas FISPQs. A finalidade dessa etapa consiste em gerar uma listagem abrangente dos riscos ambientais, verificando as Revista Produção Online. Florianópolis, SC, v. 18, n. 2, p. 620-640, 2018. 
áreas de impacto, causas e consequências potenciais fatores necessários para a análise de riscos (ABNT, 2009).

\section{Etapa 2 - Análise de riscos}

Nessa etapa ocorreu a apreciação das causas (perigos), fontes, consequências e a probabilidade de ocorrência, fatores determinantes para a classificação do risco, o que motiva uma perspectiva de tomada de decisão mais adequada (ABNT, 2009). A classificação sucedeu por tipologia e prioridade de tomada de decisão. Foram estabelecidos critérios classificatórios para os Riscos de Segurança de Processos (RSP), Risco à Saúde Humana (RSH) e Risco Ecológico (RE) (SERPA, 2000).

Continuamente foram identificadas as prioridades quanto aos riscos identificados e classificados. O PMI (2013) e Jung e Roh (2017) recomendam metodologias com o uso de fatores como tendência e severidade para a classificação do risco, formatados numa matriz de probabilidade. Assim, como método para o reconhecimento das prioridades, aplicou-se a matriz de gravidade, urgência e tendência (GUT), o que possibilita a inclusão da relevância e da urgência na tomada de decisão. Conforme Viana et al. (2013), a matriz GUT trata-se uma ferramenta de simples aplicação e de grande utilidade para fixação de prioridades na eliminação de problemas, com a finalidade de orientar as decisões mais complexas, através da multiplicação de níveis de gravidade, urgência e tendência.

Dessa forma, com o auxílio do Microsoft Excel 2013, estabeleceu-se uma listagem dos perigos e riscos, elencados em níveis de gravidade ou severidade, de urgência e de tendência ou probabilidade, na qual a pontuação máxima é de 5 e mínima, de 1, com escala de 1 (Quadro 1).

Quadro 1 - Pontuação da matriz GUT
\begin{tabular}{|llll|}
\hline PESO & GRAVIDADE (G) & \multicolumn{1}{c|}{ URGÊNCIA (U) } & \multicolumn{1}{c|}{ TENDÊNCIA (T) } \\
\hline 1 & sem gravidade & sem urgência & não há incidências históricas \\
2 & pouco grave & pouco urgente & $\begin{array}{l}\text { já ocorreu historicamente poucas } \\
\text { vezes }\end{array}$ \\
3 & grave & urgente & ocorre com frequência \\
4 & muito grave & muito urgente & ocorre com alta frequência \\
5 & extremamente grave & extremamente & sempre ocorre \\
& & urgente & \\
\hline
\end{tabular}

Fonte: Adaptado de Grimaldi e Mancuso (1994)

Os valores atribuídos proporcionaram o produto entre GxUxT, com pontuação máxima de 125 e mínima de 1, apresentados com sinalizações de cores diferente ao grau de prioridade (Quadro 2). 
Quadro 2 - Escala de prioridades

\begin{tabular}{|ccc|}
\hline G x U X T & SINALIZAÇÃO & PRIORIDADES \\
\hline 125 a 101 & & extrema \\
100 a 76 & & alta \\
75 a 51 & média \\
50 a 26 & regular \\
25 a 1 & baixa \\
\hline
\end{tabular}

Fonte: Adaptador de Grimaldi e Mancuso (1994).

Os riscos foram listados em ordem decrescente, proporcionando a apresentação das prioridades. Foram considerados como riscos potenciais, aqueles que os resultados da matriz GUT superior a 51, sendo de prioridade média; os demais são classificados como insignificantes. A partir do ordenamento dos riscos com bases em prioridades realizou-se a avaliação de riscos.

\section{Etapa 3 - Avaliação de riscos}

A partir da listagem em ordem decrescente de prioridade, indicou-se as medidas preventivas para atuação nas causas (perigos), e as corretivas para sanar os riscos ocorridos. Os potenciais riscos foram representados graficamente no layout das instalações produtivas, utilizando a mesma escala de cor. As ações foram tipificadas pelas estratégias de respostas aos riscos (Quadro 3).

\begin{tabular}{|c|c|}
\hline Estratégia & Significado da estratégia \\
\hline Mitigação & $\begin{array}{l}\text { Reduz a probabilidade do } \\
\text { risco }\end{array}$ \\
\hline Eliminação & Eliminar a causa do problema \\
\hline Prevenção & Controlar o risco \\
\hline Redução & Reduzir o impacto \\
\hline Transferir & Transferir o risco para terceiro \\
\hline Aceitar & Aceitar os impactos \\
\hline
\end{tabular}

Para a ABNT NBR ISO 31.000:2009, as ações são focadas para a mitigação, a eliminação, a prevenção e a redução do risco (ABNT, 2009). Já para Scofano et al. (2013), as estratégias em resposta aos riscos podem mitigar, aceitar ou evitar a ocorrência dos riscos, até o nível de evidenciar a transferência de responsabilidade. Desta forma, há várias alternativas além da normativa. 


\section{RESULTADOS E DISCUSSÕES}

Os resultados foram alcançados e agrupados em etapas de forma a facilitar a aplicação do modelo de gestão proposto. Iniciou-se o reconhecimento dos processos, inputs e outputs, fatores considerados primordiais para a identificação dos riscos.

\section{Etapa 1 - Identificação de riscos}

De forma simplificada, pode-se descrever o processo de beneficiamento das peças de jeans na lavanderia estudada, iniciando pela recepção do produto bruto, dando star ao processo. A primeira atividade produtiva é a lavagem, na qual as peças são inseridas nas máquinas de lavar de porte industrial, sucedendo a desengomagem, o alvejamento e a coloração, com a ação de produtos químicos. As peças podem passar por quantas lavagens forem necessárias, a fim de alcançar as solicitações dos clientes.

Posteriormente, segue para a secagem e centrifugação, atividades que promovem a retirada da umidade, tornando a peça seca para a execução do acabamento. São vários os tipos de acabamento, inclusive o efeito used, que permite a descoloração de parte da peça, utilizando componentes químicos. Após esse efeito, o produto segue novamente para a lavagem, neutralizando os produtos químicos e acrescentando amaciantes. No momento em que as peças são consideradas acabadas, seguem para a passagem com o ferro a vapor (oriundo das produções das caldeiras). Como resultado, foi elaborado fluxograma agrupado com imagens fotográficas representativas dos perigos, o que permite a visualização mais simplificada dos processos e das consequências (Figura 3). 
Figura 3 - Fluxograma dos processos produtivos da lavanderia

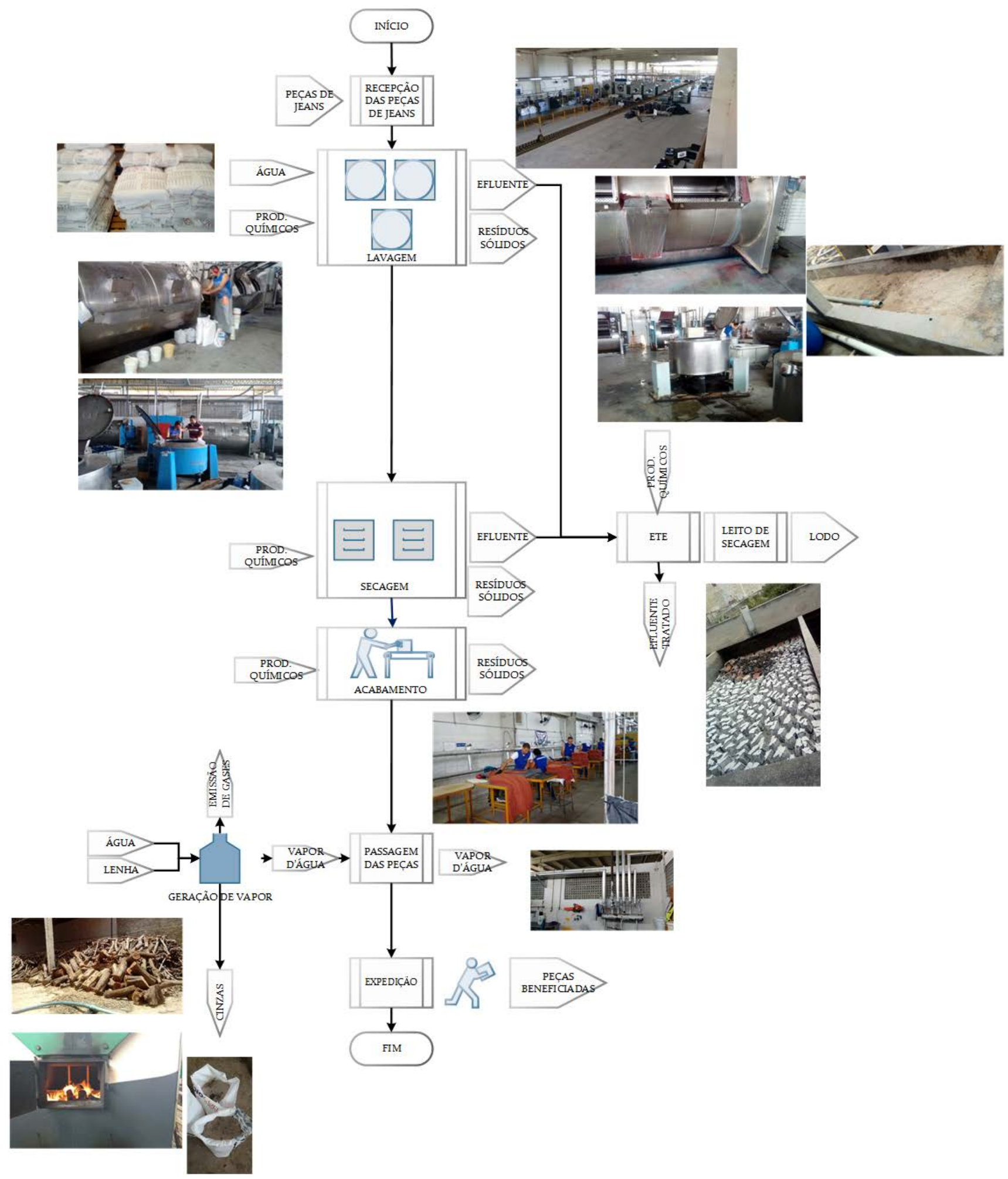

Fonte: autor

Conforme Rehacek (2017) identificar riscos é um processo dinâmico, visto que os riscos podem evoluir ou só se tornar conhecido ao longo do ciclo de vida. 


\section{Etapa 2 - Análise de riscos}

A posse do fluxograma permitiu detectar as etapas, as causas e os riscos (efeitos) relativos aos perigos, como também estabelecer uma categorização por tipo de impacto. $\mathrm{Na}$ investigação foram identificados 53 riscos no total dos processos (Tabela 1).

\begin{tabular}{|c|c|c|c|c|}
\hline Etapa do processo & RE/IA & RSH & RSP & Total \\
\hline Lavagem & 6 & 5 & 1 & 12 \\
\hline Secagem & 3 & 3 & 1 & 7 \\
\hline Acabamento & 4 & 2 & 0 & 6 \\
\hline Passagem & 0 & 2 & 0 & 2 \\
\hline $\begin{array}{l}\text { Estação de tratamento de } \\
\text { efluente }\end{array}$ & 5 & 3 & 1 & 9 \\
\hline Leito de secagem & 3 & 0 & 0 & 3 \\
\hline Geração de vapor & 6 & 5 & 0 & 11 \\
\hline Demais processos & 0 & 3 & 0 & 3 \\
\hline Total & 27 & 23 & 3 & 53 \\
\hline
\end{tabular}

Os impactos ambientais tiveram a maior representatividade (51\%), seguidos pelos ricos à saúde humana $(44,6 \%)$ e pelos à segurança de processos (5,4\%). Na atividade de lavagem, os riscos ecológicos encontrados foram de impactos na contaminação de corpos hídricos, devido a destinação insuficiente do efluente e pela presença de metais pesados ( $\mathrm{Cu}, \mathrm{Cr}, \mathrm{Al}, \mathrm{Fe}, \mathrm{As}, \mathrm{Mn}$ e $\mathrm{Ph}$ ), oriundos de produtos químicos (PQ) identificados pelas FISQs apresentadas, reforçado por Silva, Barros e Rezende (2005). Segundo Herek et al. (2009), os corantes que não se aderem à fibra durante o tingimento são descartados durante as etapas de lavagem. Similarmente, por esse motivo, pode ocorrer a contaminação de solo, devido ao descarte de embalagem de $\mathrm{PQ}$ incorretamente e ao vazamento de óleo, de lubrificantes ou de produtos químicos. Quanto à saúde humana, os riscos estão relacionados às doenças dermatológicas e pneumáticas pelo contato com $\mathrm{PQ}$, à queda por diferença de nível, à perda ou ao corte de membros e ao choque elétrico na operação das máquinas lavadoras de peças. Por último, na lavagem do jeans, o risco a segurança do processo relativo à gestão de energia está focado na capacidade de gerar desperdícios processuais energéticos.

Durante o processo de secagem e centrifugação, os riscos assemelham-se aos da etapa anterior, devido a equivalência nas entradas e saídas de insumos químicos; porém os químicos desses processos não possuem cargas de metais pesados, observados pelas FISQs. Na fase de acabamento, observam-se quatro riscos classificados como ecológicos 
por contaminação de solo e de corpos hídricos, com possibilidade de presença de metais pesados $(\mathrm{Mn})$ quando da aplicação do permanganato de potássio para realização do used (efeito aplicado a peça ficar com características de jeans envelhecido). Os outros dois ocorrem quanto à segurança humana, originados pelo perigo no manuseio de ferramentas e equipamentos perfurantes ou cortantes, o que pode suscitar corte ou perda de membros, além do uso de químicos com características a provocar doenças relacionadas ao contato com esse metal pesado.

Ainda, na atividade de passagem das peças, observa-se a perspectiva de queimaduras leves a médias, causados pela operação incorreta dos ferros de engomar e choque elétrico por vazamento de corrente, o que totaliza dois riscos nessa etapa.

Os efluentes são tratados, o que minimiza os impactos ambientais; porém não eliminar os riscos ecológicos por contaminação de corpos hídricos e no solo, pois a empresa utiliza o tratamento primário em estação própria, o que a Resolução Conama n. 430/2011 determina como exigência mínima para tal situação (CONAMA, 2011). Foram vistos três riscos quanto à segurança humana, pela presença de maquinários à eventualidade de choque elétrico, de desníveis que podem produzir quedas e de contato com produtos químicos. Segundo Herek et al. (2009), alguns tipos de floculantes utilizados no tratamento do efluente podem conter metais pesados, o que tem potencialidade de provocar risco à saúde humana. No leito de secagem, todos os três riscos foram de contaminação de solo por lodo, pela percolação de líquidos no solo e potencial contato com corpos hídricos.

Para a geração de vapor, identificaram-se seis impactos ambientais e cinco de segurança humana. Nos ecológicos, observou-se o desmatamento da flora local quando da aquisição de lenha fora dos padrões legais, à contaminação do ar por emissão de gases durante a queima de madeira ou outros produtos empregados como matriz energética, a contaminação do solo no caso de destinação inadequada das cinzas. Brito (2013) comenta que a queima da lenha compromete a qualidade do ar, uma vez que promove a emissão de dióxido de carbono $\left(\mathrm{CO}_{2}\right)$ em excesso na atmosfera, aumentando a temperatura. Os relativos a segurança compreendem danos humanos e materiais em caso de explosão da caldeira, causando queimaduras graves, médias ou leves, de choque elétrica pela presença de maquinário e de desconforto térmico pela geração de vapor.

No ambiente fabril, foi possível notar riscos de queimadura leves a médias pelo acesso aos tubos de passagens de vapor em vários ambientes e a ocorrência de desnível que pode provocar quedas por diferença de nível. 
Já nas etapas produtivas com mais riscos definidos foram a lavagem e a geração de vapor, totalizando $45,3 \%$ dos itens apresentados. Verificam-se repetições, porém, com causas diferentes e em locais de incidência variada. Nos ecológicos, 23 itens são impactos de contaminação de corpos hídricos e solo, na maioria, por uso de produtos químicos. Ressalta-se que os riscos ecológicos são representativos, visto terem sido observados em maior quantidade, não tendo sido realizada analise de intensidade do dano potencial.

É importante comentar que dos 53 riscos levantados, apenas onze foram pontuados acima de 51 na escala de prioridade, o que os tornam potenciais, sendo quatro desses classificados como de "extrema prioridade" e dois de "alta prioridade", nos quais devem proceder ações imediatas e monitoramento. Os cinco itens classificados com "média prioridade", podem ter programação definida e controlada (Quadro 5).

Os 42 riscos restantes, foram classificados entre "regular" e "baixa prioridade", foram considerados como insignificantes. Esses não podem ser desconsiderados, pois quando agrupados ou em volume de incidência elevada, podem se tornar danosos. Como no caso dos riscos de contaminação de corpos hídricos e solo, muito embora com baixa prioridade, estes podem acarretar danos sociais e econômicos, além de ecológicos.

Assim, como determina a Lei n. 9.605, de 12 de fevereiro de 1998, a poluição decorrente de lançamento de resíduos sólidos, líquidos ou gasosos, em desacordo com as exigências considera-se crime ambiental e tem suas penalidades estabelecidas (BRASIL, 1998). Baseado neste preceito, em outubro de 2009, em Caruaru, 14 lavanderias foram interditadas pela acusação de crime ambiental. Tal fato ocorreu devido a estas não trataram corretamente o efluente, embora algumas possuírem estação de tratamento, mas não utilizavam para economizar energia, insumo e água no processo (SILVA et al., 2012). Tais riscos devem levar em consideração análises mais complexas, buscando definir medidas preventivas ou corretivas.

Conforme Silva et al. (2017) a análise de riscos tem como objetivo entender o risco e determinar seu nível, quanto que a avaliação do risco comparar os resultados da análise de riscos. 
Quadro 5 - Lista de riscos por grau de prioridade

\begin{tabular}{|c|c|c|c|c|c|}
\hline Etapa do processo & Risco (efeito) & G & $\mathbf{U}$ & $\mathbf{T}$ & Prioridade \\
\hline Lavagem & $\begin{array}{l}\text { Contaminação de corpos hídricos por poluição do } \\
\text { efluente por carregamento de metais pesados }\end{array}$ & 3 & 3 & 2 & 18 \\
\hline Lavagem & $\begin{array}{l}\text { Doenças dermatológicas e doenças diversas por } \\
\text { contato dos químicos por pessoal não atuante de } \\
\text { processo }\end{array}$ & 3 & 4 & 4 & 48 \\
\hline Lavagem & Queda de pessoal & 2 & 4 & 3 & 24 \\
\hline $\begin{array}{l}\text { Lavagem, Secagem e } \\
\text { ETE }\end{array}$ & Desperdício de energia & 1 & 2 & 2 & 4 \\
\hline Lavagem & $\begin{array}{l}\text { Contaminação de solo por destinação inadequada } \\
\text { de resíduos perigosos }\end{array}$ & 3 & 3 & 2 & 18 \\
\hline Lavagem e Secagem & Corte ou perda de membros & 5 & 4 & 5 & 100 \\
\hline $\begin{array}{l}\text { Lavagem, Secagem, } \\
\text { ETE e Passagem das } \\
\text { peças }\end{array}$ & Choque elétrico & 4 & 4 & 4 & 64 \\
\hline Lavagem & Contaminação de águas subterrânea ou solo & 2 & 3 & 2 & 12 \\
\hline Lavagem & Contaminação de corpos hídricos e solo & 3 & 3 & 2 & 18 \\
\hline Lavagem e Secagem & $\begin{array}{l}\text { Contaminação de solo e águas por destinação } \\
\text { inadequada de resíduos perigosos }\end{array}$ & 2 & 3 & 2 & 12 \\
\hline Secagem e ETE & Queda de pessoal & 3 & 4 & 3 & 36 \\
\hline Secagem & $\begin{array}{l}\text { Contaminação de solo por destinação inadequada } \\
\text { de resíduos perigosos }\end{array}$ & 3 & 3 & 2 & 18 \\
\hline Secagem e ETE & Contaminação de corpos hídricos e solo & 3 & 3 & 2 & 18 \\
\hline ETE & $\begin{array}{l}\text { Contaminação de corpos hídricos por poluição do } \\
\text { efluente por carregamento de metais pesados }\end{array}$ & 3 & 3 & 2 & 18 \\
\hline ETE & $\begin{array}{l}\text { Contaminação de solo por destinação inadequada } \\
\text { de resíduos perigosos }\end{array}$ & 3 & 3 & 2 & 18 \\
\hline Lavagem e ETE & $\begin{array}{l}\text { Doenças dermatológicas e doenças diversas por } \\
\text { contato dos químicos }\end{array}$ & 2 & 4 & 4 & 32 \\
\hline ETE e Acabamento & $\begin{array}{l}\text { Contaminação de solo e águas por destinação } \\
\text { inadequada de resíduos perigosos }\end{array}$ & 2 & 3 & 2 & 12 \\
\hline Leito de secagem & $\begin{array}{l}\text { Contaminação de solo e águas por percolação de } \\
\text { líquidos }\end{array}$ & 2 & 3 & 2 & 12 \\
\hline $\begin{array}{l}\text { Leito de secagem, } \\
\text { Acabamento e } \\
\text { Geração de vapor }\end{array}$ & Contaminação de solo & 2 & 3 & 2 & 12 \\
\hline Acabamento & Corte ou perda de membros & 3 & 4 & 5 & 60 \\
\hline Acabamento & $\begin{array}{l}\text { Contaminação de corpos hídricos por poluição do } \\
\text { efluente por carregamento de metais pesados - } \\
\text { efeito de used }\end{array}$ & 3 & 3 & 2 & 18 \\
\hline Acabamento & Doenças cancerígenas & 5 & 4 & 4 & 80 \\
\hline Geração de vapor & Desmatamento da flora local & 2 & 2 & 2 & 8 \\
\hline Geração de vapor & Contaminação do ar por emissão de gases & 2 & 3 & 2 & 12 \\
\hline Geração de vapor & $\begin{array}{l}\text { Contaminação do ar por emissão de gases } \\
\text { contaminantes }\end{array}$ & 3 & 3 & 3 & 27 \\
\hline Geração de vapor & Queimaduras graves & 5 & 4 & 5 & 100 \\
\hline Geração de vapor & Desconforto térmico & 3 & 3 & 2 & 18 \\
\hline $\begin{array}{l}\text { Geração de vapor e } \\
\text { Toda a fábrica }\end{array}$ & Queimaduras de leve a média & 3 & 3 & 2 & 18 \\
\hline Geração de vapor & Desconforto térmico & 2 & 3 & 2 & 12 \\
\hline Geração de vapor & Provocar ilha de calor & 2 & 2 & 2 & 8 \\
\hline Geração de vapor & Danos materiais e humanos & 5 & 5 & 5 & 125 \\
\hline Geração de vapor & Choque elétrico & 4 & 4 & 5 & 80 \\
\hline Passagem das peças & Queimaduras leves a médias & 3 & 3 & 3 & 27 \\
\hline Toda a fábrica & Queda por desnível & 2 & 3 & 2 & 12 \\
\hline
\end{tabular}

Fonte: autor

Revista Produção Online. Florianópolis, SC, v. 18, n. 2, p. 620-640, 2018. 


\section{Etapa 3 - Avaliação de riscos}

As análises de risco fornecem argumentos para avaliações de ações que, a priori, devem ser consideradas e tratadas com base nas estratégias adequadas, envolvem a estimativa de potenciais consequências e de probabilidades associadas, permitindo medir os níveis (KRZEMIEN et al., 2015). Para os potenciais riscos, foram apontadas medidas preventivas e corretivas, sinalizando as estratégias especificadas para as ações (Quadro $6)$.

Percebe-se que todas as ações corretivas são tipificadas como de aceitação, visto que a medida corretiva é tomada no caso do problema já ter de fato ocorrido, não havendo outra alternativa a ser tomada. A seleção da estratégia de gestão de risco não é simples, precisa-se investigar as diferentes alternativas viáveis através do processo de análise (KRZEMIEN et al., 2016). A estratégia corretiva encontra-se alinhada a tomada de decisão da organização (REHACEK, 2017).

O processo de geração de vapor reúne $27 \%$ de potencialidade das ocorrências, podendo ser considerada a área mais crítica em grau de risco, motivado para utilização de caldeira de vapor (Figura 4). 
Quadro 6 - Medidas preventivas e corretivas

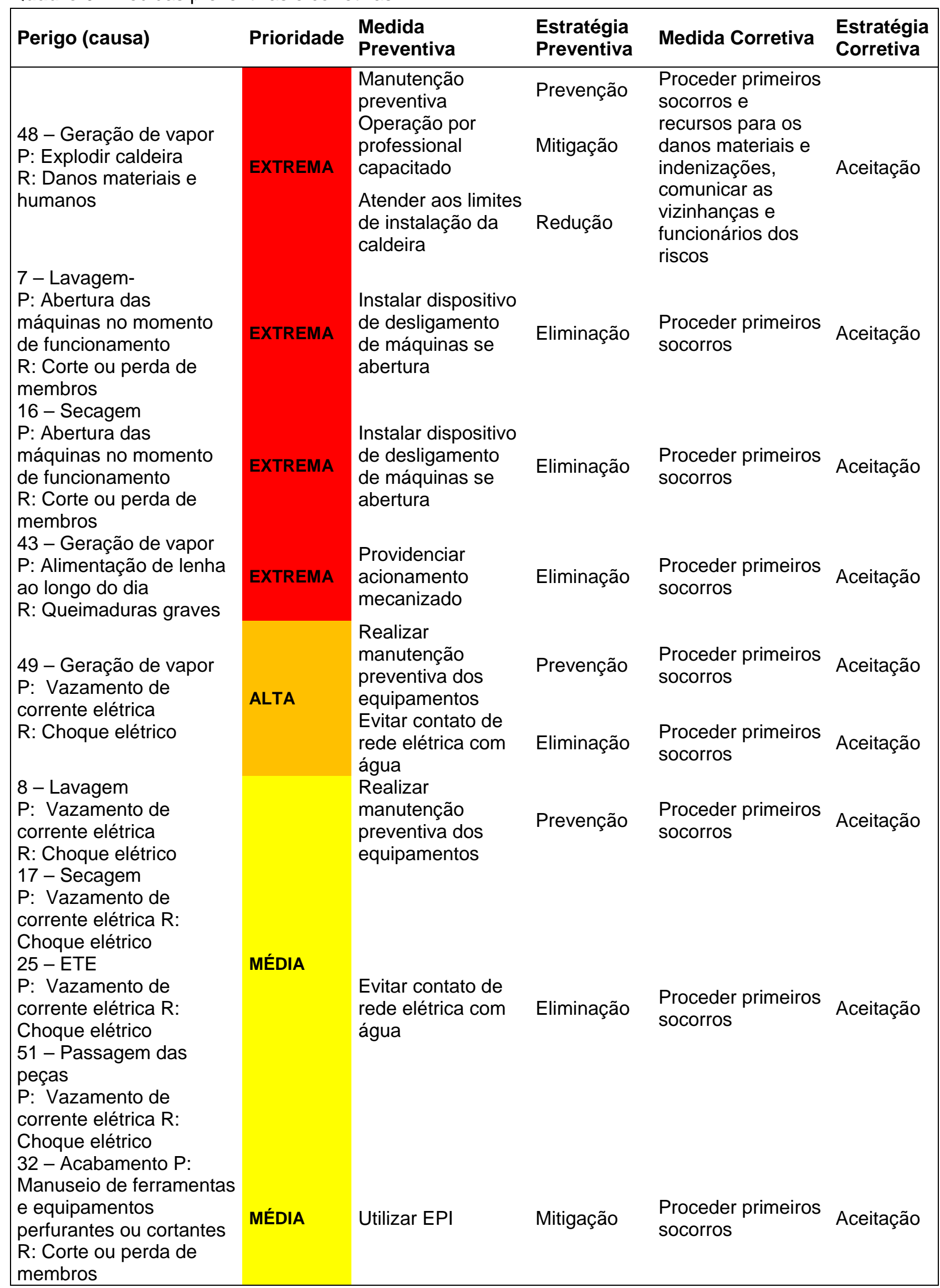

Legenda: P- Perigo; R-Risco.

Fonte: autor

Revista Produção Online. Florianópolis, SC, v. 18, n. 2, p. 620-640, 2018. 
Figura 4 - Desenho sem escala (layout) da indústria com a sinalização de riscos potenciais.
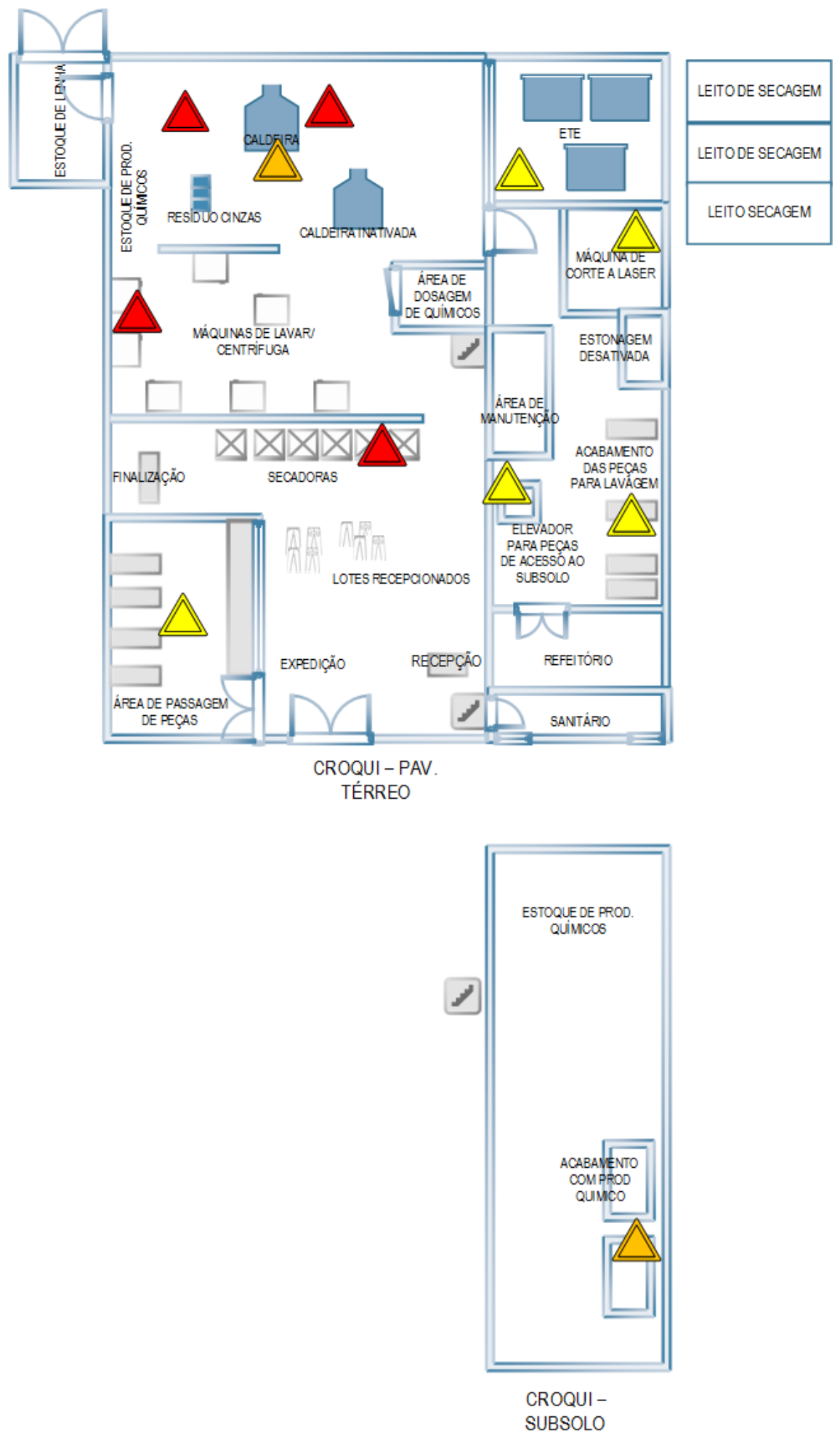

Identificar no layout as áreas de risco segundo as medidas preventivas e corretivas é relevante para que, de forma visual, o gestor possa ter ciência de como proceder, além desta ferramenta auxiliar na tomada de decisão quando da ocorrência de sinistro. Este mapa deve ser colocado em local de fácil visualização para que todos da equipe possam ter conhecimento dos riscos potenciais relativos a cada área do empreendimento. 
Gehlen e Silva (2010) registram o número de quatro mortes no período de seis anos por explosão de três caldeiras na cidade de Toritama, cidade localizada no mesmo APL. Neste município, a maioria das lavanderias está instalada em local inadequado, como nos quintais das residências, o que torna iminente o risco. Segundo a Norma Regulamentadora do Ministério do Trabalho, as caldeiras de geração de vapor devem ser instaladas no mínimo 3 metros das outras instalações do estabelecimento, de depósitos de combustíveis, do limite de propriedade do terreno e das vias públicas, buscando a segurança das instalações por meio de manutenções preventivas, por profissional habilitado (MINISTÉRIO DO TRABALHO, 2014).

Neste sentido, aprofundar o conhecimento deste APL é de fundamental relevância para elevar o nível de segurança operacional do setor, assim como agregar valor aos produtos e serviços oferecidos na região. Além do mais, o gerenciamento dos riscos eleva a segurança social, econômica e ambiental desta localidade, assim como assegura que o setor evitará possíveis eventos negativos, potenciais para comprometer a imagem junto aos consumidores em geral. Tal prática de análise dos riscos e determinação de modus operandis que denote maior grau de segurança deve ser uma prática incentivada pelos diversos segmentos que direta ou indiretamente influenciam no APL têxtil e de confecção do Agreste pernambucano.

\section{CONCLUSÃO}

A aplicação de um modelo de gestão de risco ambiental APL têxtil e de confecção do Agreste pernambucano, especificamente nas lavandeiras de jeans, localizadas na cidade de Caruaru, mesmo que preliminarmente, foi considerada satisfatória, tendo em vista o atendimento e a simplificação as etapas estabelecidas para atendimento aos requisitos propostos pela ABNT NBR ISO 31.001. As ferramentas utilizadas apresentaramse de fácil utilização, podendo ser complementares a aplicação de metodologias de elevação da segurança operacional das indústrias do APL.

Dentre os riscos identificados, observou-se que a tipologia com maior representatividade foram os ecológicos (51\%), seguido dos de segurança humana (44,6\%) e de processo (5,4\%), sendo menos significante neste último caso. Apesar de identificados pequenos riscos, esses devem ter observados face ao potencial acumulativo ou de combinação com outros riscos. 
Em relação aos setores das indústrias, a de lavagem e a de geração de vapor apresentaram maior incidência de riscos (45,3\%), ressaltando que a presença da caldeira denota cuidados especiais face a intensidade potencial do dano.

Entende-se que a gestão de risco é a algo dinâmico, que deve ser executado periodicamente, com acompanhamento ao longo das fases produtivas, face o atrelamento com o fluxo de operação dos processos. Embora a gestão de risco seja de fundamental importância para as indústrias de beneficiamento de jeans, as maiores dificuldades estão relacionadas à ausência de quadro de pessoas capacitadas para a gestão, como também sensibilização para a necessidade de aplicação das ações.

Pretende-se que este estudo seja observado pelos envolvidos direta e indiretamente com as atividades do APL têxtil e de confecção do Agreste pernambucano, assim como se reconhece que há a necessidade de maior aprofundamento da questão para que o segmento continue crescendo e gerando riquezas e trabalho para a região.

\section{REFERÊNCIAS}

ABNT. Associação Brasileira de Normas Técnicas. NBR ISO 31.000 - Gestão de riscos - Princípios e diretrizes. ABNT, Rio de Janeiro, 2009.

ALVES, N. A. Guia de resolução de problemas. Rio de Janeiro: Qualitymark. Ed.1995. 60p.

BRASIL. Lei n. 9.605, de 12 de fevereiro de 1998. Dispõe sobre as sanções penais e administrativas derivadas de condutas e atividades lesivas ao meio ambiente, e dá outras providências. Diário Oficial [da] República Federativa do Brasil, Poder Executivo, Brasília, DF, 13 de fev. 1998. Acesso em 01 de fevereiro de 2017. Disponível em: http://www.planalto.gov.br/ccivil 03/leis/L9605.htm

BRITO, G. A. Sustentabilidade: um desafio para as lavanderias industriais. Revista de Design Inovação e Gestão Estratégica, v. 4, n. 2, 2013.

CONAMA. Resolução CONAMA n. 1, de 23 de janeiro de 1986. Dispõe sobre critérios básicos e diretrizes gerais para a avaliação de impacto ambiental. Diário Oficial da República Federativa do Brasil, Poder Executivo, Brasília, DF, seção I, p. 2548 - 2549, 17 de fev. 1986. Acesso em: 02 de mar.2017. Disponível em: http://www.mma.gov.br/port/conama/res/res86/res0186.html

CONAMA. Resolução CONAMA n. 430, de 13 de maio de 2011. Dispõe sobre condições e padrões de lançamento de efluentes. Diário Oficial da República Federativa do Brasil, Poder Executivo, Brasília, DF, no 92, p. 89, 16 de maio de 2011, pág. 89. Acesso em: 02 de mar. 2017. Disponível em: http://www.mma.gov.br/port/conama/legiabre.cfm?codlegi=646

ELBARKOUKY, M. M. G.; FAYEK, A. R.; SIRAJ, N. B.; ; SADEGHI, N.. Fuzzy Arithmetic Risk Analysis Approach to Determine Construction Project Contingency. Journal of construction engineering and management, v. 142. n. 12, Dec. 2016.

DOI:http://dx.doi.org/ 10.1061/(ASCE)CO.1943-7862.0001191 
GEHLEN, V. R. F.; SILVA, A. R.. O rio tem a cor da moda: os impactos nas águas do rio Capibaribe ocasionados pelas lavanderias industriais. In: Conferência Internacional da Rede WATERLAT, São Paulo, 2010.

GRIMALDI, R.; MANCUSO, J. H.. Qualidade total. Folha de SP e Sebrae, 6º e $7^{\circ}$ fascículos, 1994.

HEREK, L. C. S.; SILVA JUNIOR, A. T., PAVEZZI, C. C..; BERGAMASCO, R.; TAVARES, C. R. G. Incorporação de lodo de lavanderia industrial na fabricação de tijolos cerâmicos. Revista

Cerâmica, n. 55, 2009.

JUNG, K.; ROH, M.. A study for an appropriate risk management of new technology deployment in Nuclear Power Plants. Annals of Nuclear Energy, v. 99, p. 157-164, 2017.

DOI: https://doi.org/10.1016/j.anucene.2016.08.013

KRZEMIEN, A.; SANCHEZ, A.. S.; FERNANDEZ, P. R.; ZINMERMANN, K.; COTO, F. G.Towards sustainability in underground coal mine closure contexts: A methodology proposal for environmental risk management. Journal of Cleaner Production, v. 139, p. 1044-1056, 2016.

DOI: https://doi.org/10.1016/j.jclepro.2016.08.149

MTE. Ministério do Trabalho. Portaria MTE $n .^{\circ}$ 594, de 28 de abril de 2014, Norma regulamentadora13- Caldeiras, vasos de pressão e tubulações. Ministério do trabalho, 2014. Acesso em 02 de janeiro de 2017. Disponível em:

http://trabalho.gov.br/images/Documentos/SST/NR/NR13.pdf

MTE. Ministério do Trabalho. Portaria SSST n. ${ }^{\circ}$ 25, 29 de dezembro de 1994, NR 9 - Programa de Prevenção de Riscos Ambientais (PPRA). Ministério do trabalho, 2014. Acesso em 02 de janeiro de 2017. Disponível em: http://trabalho.gov.br/images/Documentos/SST/NR/NR9.pdf

OLECHOWSKI, A.; OEHMEN, J.; SEERING, W.; BEN-DAYA, M. The professionalization of risk management: What role can the ISO 31000 risk management principles play. International Journal of Project Management, v. 34, n. 8, p. 1568-1578, 2016.

DOI: https://doi.org/10.1016/j.ijproman.2016.08.002

OLIVEIRA, U. R.; MARINS, F. A. S.; ROCHA, H. M.; SALOMON, V. A. P. The ISO 31000 standard in supply chain risk management. Journal of Cleaner Production, v. 151, p. 616-633, 2017.

DOI: https://doi.org/10.1016/i.jclepro.2017.03.054

PMI, Project Management Institute. Um guia do conhecimento em gerenciamento de projetos (GUIA PMBOK). PMI, 5a edição. EUA: Pennsylvania, 2013.

PYRGIDIS, C.; PAPACHARITOU, E.; ELEFTHERIADIS, A. Risk Management at Railroad Grade Crossings: Proposal for a Decision Support System.Transportation Research Procedia, v.14, p. 1394-1402, 2016.DOI: https://doi.org/10.1016/j.trpro.2016.05.212

REHACEK, P. Risk management standards for project management. International Journal of Advanced and Applied Sciences, v, 4, n. 6, p. 1-13, 2017.

DOI: https://doi.org/10.21833/ijaas.2017.06.001

ROCHA, R. M.; SILVA JUNIOR, L. H.; VIANA, J. A. B. Inovação e competição: um estudo de caso do arranjo produtivo de confecção do agreste pernambucano. Gestão e Desenvolvimento em Revista, v.1, n.1, p. 50-80, jun/2015.

SCOFANO, C. R. F.; ABRAHAM, E. F.; SILVA, L. S.; TEIXEIRA, M. A. Gestão de risco RM projetos: Análise das etapas do PMI-PMBOK (Project Management Institute). In:CONGRESSO ONLINE DE ADMINISTRAÇÃO, 11., 2013, Brasília. Anais.... 2013. 
SERPA, R. As metodologias de análise dos riscos e seu papel no licenciamento de indústrias e atividades perigosas. In: FREITAS, C. et al. (Org.). Acidentes industriais ampliados: desafios e perspectivas para o controle e a prevenção. Rio de Janeiro: Ed. Fiocruz, 2000.

SILVA, G. L.; BARROS, C. R.; REZENDE, R. B. Diagnóstico ambiental das lavanderias de jeans de Toritama. CONGRESSO BRASILEIRO DE ENGENHARIA SANITÁRIA E AMBIENTAL, 23., 2005.Anais...Campo Grande, Minas Gerais, 2005.

SILVA, L. M. F.; OLIVEIRA, A. C. R.; LEITE, M. S. A.; MARINS, F. A. Avaliação do risco na cadeia de suprimento: um estudo exploratório no setor alimentício. Revista Produção Online, Florianópolis, SC, v. 17, n. 1, p. 351-375, 2017. DOI: http://dx.doi.org/10.14488/1676-1901.v17i1.2559

SILVA, M. V. A.; SILVA, A. L.; BRITO, D. J. M.; BRANCO, D. K. S.; FERREIRA M. O. A Questão Ambiental no polo de confecções de Caruaru: Um primeiro ensaio à luz dos instrumentos econômicos de proteção ambiental. Revista Estudos do CEPE, Santa Cruz do Sul, v. 35, p. 108132, 2012. DOI: http://dx.doi.org/10.17058/cepe.v0i35.2389

TRIVIÑOS, A. N. S. Introdução à pesquisa em ciências sociais: a pesquisa qualitativa em educação. São Paulo: Atlas, 1987.

VIANA, A. D.; SILVA, D. B.; MUCHA, J.; POLACINSKI, E. Ferramentas da qualidade: proposta para melhorar resultados em uma empresa especializada em tecnologia da informação. SIEF - Semana Internacional das Engenharias da FAHOR, 3., 2013. Anais... out/2013.

Yuan, X.; Wei, Y.; Wang, B.; Mi, Z. Risk management of extreme events under climate change. Journal of Cleaner Production. v.166, n. 10, p. 1169-1174, 2017.

DOI:https://doi.org/10.1016/i.jclepro.2017.07.209

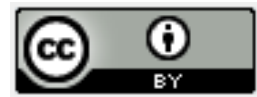

Artigo recebido em 23/05/2017 e aceito para publicação em 01/12/2017

DOI: http://dx.doi.org/10.14488/1676-1901.v18i2.2881 